\title{
El Salvador: Quince AÑos de la Firma de loS Acuerdos de Paz
}

\author{
El Salvador: Fifteen Years After the Signing of the Peace Accords
}

\section{CARLOS G. RAMOS}

FLACSO-El Salvador

\section{NAYELLY LOYA}

FLACSO-El Salvador

\begin{abstract}
RESUMEN
En el año 2007 El Salvador celebró quince años de la firma de los acuerdos de paz, hecho que permitió perfilar, al menos coyunturalmente, un escenario positivo para la búsqueda de acuerdos que permitieran solventar problemas como la delincuencia y la inseguridad. Sin embargo, la polarización político-partidaria imposibilitó el logro de acuerdos concretos, y más bien la dinámica política se concentró en los preparativos para las elecciones de 2009, dando paso a una prematura carrera electoral hacia la presidencia.
\end{abstract}

Palabras clave: El Salvador, elecciones, partidos políticos, gobierno, acuerdos de paz

\begin{abstract}
In 2007 El Salvador celebrated the fifteen year anniversary of the signing of the peace agreement document. This event served to establish a positive scenario where diverse agreements could be reached to solve problems such as crime and insecurity. However, political polarization did not allow for concrete agreements, but rather, by concentrating on the 2009 elections, led to a premature presidential race.
\end{abstract}

Key words: El Salvador, elections, political parties, government, peace accords.

\section{INTRODUCCIÓN}

El año 2007 estuvo marcado por una sostenida dinámica en la que el problema de la inseguridad y la violencia, así como la polarización político-partidaria, definieron las preocupaciones ciudadanas y el núcleo del hacer político. La celebración de 15 años de paz tras los acuerdos políticos de 1992 se perfiló-coyunturalmente-como un escenario positivo para la búsqueda de acuerdos que permitieran enfrentar con posiciones compartidas temas como la delincuencia y la inseguridad y a la vez abordar necesarias reformas políticas pendientes. De hecho, los principales partidos políticos realizaron algunos acercamientos orientados a este fin. Sin embargo, las posiciones encontradas entre el partido ARENA, en el gobierno, y la izquierda del FMLN impidieron llegar a acuerdos concretos. Al concluir el año, los procesos y preparativos asociados a las elecciones generales que se realizarán en 
2009 parecieron concentrar el interés y las energías de las principales fuerzas partidarias, iniciando prematuramente la carrera electoral por la Presidencia de la República y desviando en buena medida la agenda de discusión nacional hacia temas puramente electorales.

\section{LA PAZ Y EL NUEVO ESCENARIO ELECTORAL}

En el 2007 El Salvador celebró quince años de la firma de los acuerdos de paz que pusieron fin un conflicto interno de doce años y al difícil proceso de negociación llevado acabo entre el gobierno y el -en aquel momento- Frente Farabundo Martí para la Liberación Nacional (FMLN). Considerando la naturaleza eminentemente política de los contenidos del acuerdo, uno de los esfuerzos centrales a desarrollar fue el redimensionamiento y revalorización de los mecanismos electorales de lucha política. De tal suerte que tras la firma de la paz, el país logró instaurar procesos electorales con un carácter competitivo y pluralista que se han realizado en un ambiente de relativas condiciones de igualdad y con resultados, formalmente, aceptados por las partes. Así, desde 1994 a 2006, se han llevado acabo siete procesos electorales, cinco de ellos para elegir a diputados a la Asamblea General y Concejos Municipales (1994, 1997, 2000, 2003 y 2006); y tres para elegir presidente (1994, 1999 y 2004) 1 .

Todos estos eventos electorales se han caracterizado por una competencia que ha girado en torno a ARENA (el partido de derecha en el gobierno) y al FMLN (ex frente guerrillero y actualmente segunda fuerza política del país), delimitando con ello el espacio de competición de terceros partidos. En promedio, tales partidos han concentrado el $82 \%$ de los votos de las elecciones presidenciales, y el $68 \%$ en las elecciones legislativas y municipales. Ello pese a que el número de partidos contendientes en los eventos electorales nunca ha sido menor a cuatro.

En términos generales puede decirse también que a nivel nacional, para los tres tipos de elección, se ha configurado un sistema multipartidista, pues el número efectivo de partidos en promedio para el periodo de posguerra ha sido siempre mayor de dos: en elecciones presidenciales ha sido de 2,63; en legislativas de 3,5, y en Concejos Municipales de $3,59^{2}$.

Atendiendo a las características señaladas, puede sostenerse que el sistema de partido desarrollado en la postguerra ha adquirido un carácter pluralista, polarizado y de competencia bipolar. Los partidos mayoritarios representan los polos opuestos del espectro

1 El sistema electoral aplicable a cada elección es el siguiente. Las elecciones presidenciales se celebran cada cinco años, se rige por el principio de mayoría con posibilidad de segunda vuelta si no se alcanza el $51 \%$ de los votos. Se elige a Presidente y Vicepresidente de la República. Las elecciones de diputados se celebran cada tres años, en ellas rige el principio de representación proporcional y se elige a 84 diputados, los cuales representan (de acuerdo al tamaño poblacional) a cada uno de los 14 departamentos del país. Las elecciones de Concejo Municipal se celebran cada tres años, se rigen por el principio de mayoría y se eligen 262 concejos, que representan a cada uno de los 262 municipios.

2 Córdova, Ricardo; Carlos G. Ramos y Nayelly Loya (2007)."La contribución del proceso de paz a la construcción de la democracia en El Salvador (1992-2004)”. En: Azpuru, Dinorah, Ligia Blanco, Ricardo Córdova, Nayelly Loya, Carlos G. Ramos y Adrián Zapata. Construyendo la democracia en sociedades posconflicto. Guatemala y El Salvador. Un enfoque comparado. Guatemala: IDRC\&CRDI, F\&G Editores. 
ideológico, reproduciendo en el escenario electoral la confrontación que se vivió en el terreno militar.

Una mirada diacrónica a los eventos electorales de la postguerra (ver Tablas 1, 2 y 3) revela que en elecciones presidenciales ARENA ha liderado las preferencias de la población por un margen importante y sistemático. En promedio el FMLN, ha obtenido un $20 \%$ menos de los votos validos totales respecto de ARENA como se observa en el siguiente cuadro.

Tabla 1: El Salvador: elecciones presidenciales 1994-2004

\begin{tabular}{|c|c|c|c|c|c|c|c|c|}
\hline \multirow{3}{*}{ Partidos } & \multicolumn{4}{|c|}{1994} & \multirow{2}{*}{\multicolumn{2}{|c|}{$\frac{1999}{\text { Primera vuelta }}$}} & \multirow{2}{*}{\multicolumn{2}{|c|}{$\frac{2004}{\text { Primera vuelta }}$}} \\
\hline & \multicolumn{2}{|c|}{ Primera vuelta } & \multicolumn{2}{|c|}{ Segunda vuelta } & & & & \\
\hline & $\begin{array}{l}\text { Votos } \\
\text { válidos }\end{array}$ & $\%$ & $\begin{array}{c}\text { Votos } \\
\text { válidos }\end{array}$ & $\%$ & $\begin{array}{c}\text { Votos } \\
\text { válidos }\end{array}$ & $\%$ & $\begin{array}{l}\text { Votos } \\
\text { válidos }\end{array}$ & $\%$ \\
\hline ARENA & 651.632 & 49,11 & 818.264 & 68,35 & 614.268 & 51,96 & 1.314 .436 & 57,71 \\
\hline FMLN-CD-MNR & 331.629 & 24,99 & 378.980 & 31,65 & & & & \\
\hline FMLN-USC & & & & & 343.472 & 29,05 & & \\
\hline FMLN & & & & & & & 812.519 & 35,68 \\
\hline $\mathrm{PCN}$ & 70.854 & 5,34 & & & 45.140 & 3,82 & 61.781 & 2,71 \\
\hline PDC & 215.936 & 16,27 & & & 67.207 & 5,68 & & \\
\hline CDU & & & & & 88.640 & 7,50 & & \\
\hline CDU-PDC & & & & & & & 88.737 & 3,9 \\
\hline MAC & 10.901 & 0,82 & & & & & & \\
\hline MU & 31.925 & 2,41 & & & & & & \\
\hline MSN & 13.959 & 1,05 & & & & & & \\
\hline LIDER & & & & & 19.269 & 1,63 & & \\
\hline PUNTO & & & & & 4.252 &, 36 & & \\
\hline TOTAL & 1326.84 & 100,00 & 1.197.244 & 100,00 & 1.182 .248 & 100,00 & 2.277 .473 & 100,00 \\
\hline
\end{tabular}

Fuente: Córdova, et al. (2007). Op. cit.

Similar situación se observa en lo que corresponde a las elecciones de Concejo Municipal. ARENA, también ha obtenido el mayor porcentaje de votos, ganando con ello un mayor número de las alcaldías en cada elección. Sin embargo, la tendencia muestra una tendencia descendente en el número de municipios obtenidos, hasta una pequeña recuperación en las elecciones de 2006. El FMLN, por su parte, muestra una tendencia incrementar el número de los municipios obtenidos hasta el año 2000; en las dos últimas elecciones esta tendencia se ha revertido, pero sigue posicionándose como el segundo lugar, seguido por el PCN, PDC y CD/CDU. 
Tabla 2: $\quad$ El Salvador: elecciones de Concejo Municipal 1994-2006.

\begin{tabular}{|c|c|c|c|c|c|c|c|c|c|c|}
\hline \multirow{2}{*}{ Partido } & \multicolumn{2}{|l|}{1994} & \multicolumn{2}{|l|}{1997} & \multicolumn{2}{|l|}{2000} & \multicolumn{2}{|l|}{2003} & \multicolumn{2}{|l|}{2006} \\
\hline & Municipios & $\%$ & Municipios & $\%$ & Municipios & $\%$ & Municipios & $\%$ & Municipios & $\%$ \\
\hline ARENA & 206 & 78,6 & 161 & 61,5 & 132 & 50,4 & 111 & 42,4 & 147 & 56,1 \\
\hline FMLN & 14 & 5,3 & 48 & 18,3 & 73 & 27,9 & 62 & 23,7 & 54 & 20,6 \\
\hline PDC & 29 & 11,1 & 15 & 5,7 & 16 & 6,1 & 15 & 5,7 & 14 & 5,3 \\
\hline PCN & 10 & 3,8 & 18 & 6,9 & 33 & 12,6 & 52 & 19,8 & 39 & 14,9 \\
\hline $\mathrm{CDU}^{*}$ & - & - & - & - & 4 & 1,5 & 4 & 1,5 & 2 & 0,8 \\
\hline OTROS & 1 & 0,4 & 10 & 3,8 & 3 & 1,1 & 2 &, 8 & 1 & 4 \\
\hline $\mathrm{PDC} / \mathrm{PD}$ & - & - & 4 & 1,5 & - & - & - & - & - & - \\
\hline PDC/PMR/PSD & - & - & - & - & - & - & 3 & 1,1 & - & - \\
\hline PDC/PMR & - & - & - & - & - & - & 1 & , 4 & - & - \\
\hline FMLN/CD/MNR & 1 & 0,4 & - & - & - & - & - & - & - & - \\
\hline FMLN/CD* & 1 & 0,4 & 3 & 1,1 & - & - & 6 & 2,3 & 4 & 1,5 \\
\hline FMLN/CD/MU & - & - & 3 & 1,1 & - & - & - & - & - & - \\
\hline FMLN/PDC & - & - & - & - & - & - & 5 & 1,9 & 1 & 0,4 \\
\hline FMLN/AP/CDU & - & - & - & - & - & - & 1 & 0,4 & - & - \\
\hline $\begin{array}{l}\text { UNIDOS POR } \\
\text { TONACA }\end{array}$ & - & - & - & - & 1 & 0,4 & - & - & - & - \\
\hline TOTAL & 262 & 100,0 & 262 & 100,0 & 262 & 100,0 & 262 & 100,0 & 262 & 100,0 \\
\hline
\end{tabular}

Fuente: Para 1994-2003, Loya, Nayelly (2006). Distribución territorial del comportamiento electoral en elecciones de Concejo Municipal.

Para 2006, Tribunal Supremo Electoral 2006.

Diferente panorama se presenta en las elecciones legislativas donde, con excepción del año 1994, los principales partidos han obtenido similar cantidad de curules en la Asamblea (ver Tabla 3). Esta situación les ha obligado a plegarse o promover alianzas legislativas con los partidos ideológica o programáticamente cercanos, especialmente en aquellos casos donde la aprobación de proyectos o la promulgación de leyes requieren de una mayoría calificada del voto parlamentario (ver Tabla 3).

Como se ha señalado antes, en los últimos meses de 2007 la dinámica política se concentró en temas estrictamente electorales con vistas a los comicios generales de 2009. La elección bastante anticipada del periodista Mauricio Funes ${ }^{3}$ como candidato del FMLN condujo a que todo el espectro partidario se concentrara en estos temas y colocó, especialmente al partido ARENA, frente al reto de procurar un perfil definido de candidato y un método para elegirlo. 


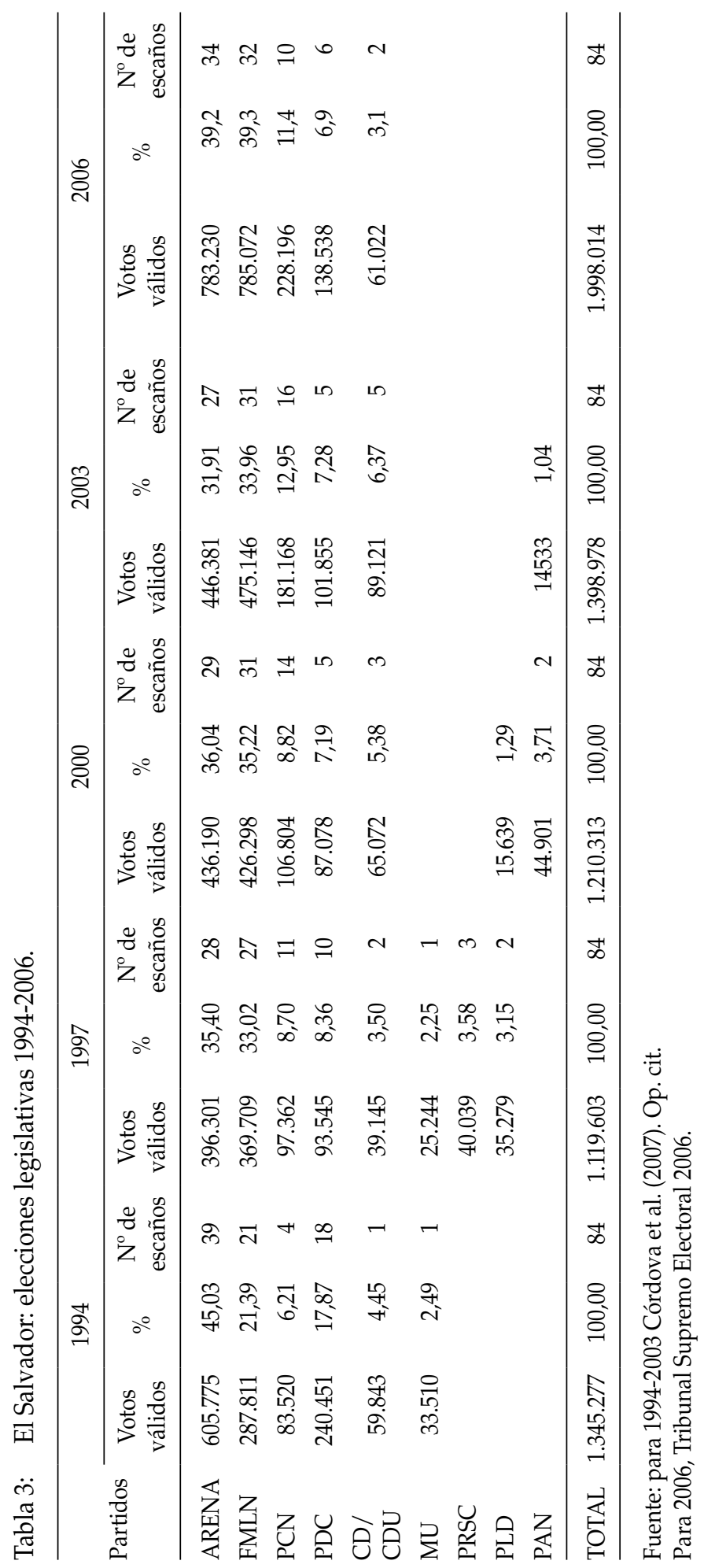


La situación generada con este hecho político condujo incluso a una modificación de las preferencias o inclinaciones de voto declaradas. Así, mientras las encuestas realizadas a principios del segundo semestre mostraban que ARENA iba a la cabeza en las preferencias electorales tanto para elecciones presidenciales, como legislativas y de concejo municipal, y el FMLN quedaba en segundo lugar,; la última encuesta realizada por el Instituto de Opinión Pública de la Universidad Centroamericana, IUDOP, señaló al FMLN como el partido que encabezaba las intenciones de voto en todos los niveles de la elección.

Con todo, los últimos acontecimientos y discusiones del año mostraron que más allá de los cambios que puedan efectuarse en las intenciones de voto, las elecciones se llevarán a cabo dentro de un ambiente altamente polarizado y que el año 2008 estará signado por esta contienda polarizada.

\section{LA COYUNTURA POLÍTICA: PAZ, VIOLENCIA Y CAMPAÑAS ELECTORALES}

El año 2007 marco la celebración de 15 años de los acuerdos de paz. Desde finales de 2006 se declaró que el mismo sería el año de la paz social al menos en dos sentidos: la celebración de los quince años de paz y el impulso de esfuerzos orientados a crear condiciones de convivencia pacífica, dados los altos índices de criminalidad.

En esta tónica, los medios de comunicación (radio, televisión y prensa) se unieron para impulsar una campaña que tendría como propósito la difusión masiva de mensajes que incentivarían a la población a convertirse en artífice de la paz desde su experiencia cotidiana. $^{5}$

Los partidos también hicieron lo suyo: a principios de enero, una comisión interpartidaria avaló por unanimidad la "Declaratoria de compromiso para consolidar la paz social y fortalecer el proceso democrático en El Salvador". En el documento se retomaron tres grandes líneas de los acuerdos de paz: (a) seguridad, que buscaría concertar y respaldar estrategias para prevenir y combatir el fenómeno delincuencial; (b) economía, impulsar un pacto fiscal que generara condiciones para la construcción de un desarrollo humano sostenible, y (c) reformas electorales, que buscarían asegurar la legitimidad del sistema. Sin embargo, pese al impulso con el que se inició, la iniciativa fracasó. En parte por las discrepancias expresadas por el partido ARENA en torno al tema económico.

Lo cierto es que una nueva oportunidad de dialogar terminó; no logró concretarse en acuerdos concretos de relevancia nacional. Así, la celebración de los quince años de paz, no tuvo el perfil deseado y terminó convirtiéndose en un motivo más de desencuentro. Por su parte, el discurso gubernamental se concentró en dar por finiquitados y cumplidos los acuerdos de paz. La posición y organizaciones sociales, por su lado, se dedicaron a denunciar el no cumplimiento del cuerpo total de acuerdos pactados.

\footnotetext{
“ARENA lidera intención de voto", La Prensa Gráfica, 28 agosto, 2007.

Semanario Proceso No 1229 , febrero 14, 2007, p. 9.
} 
Pasada la coyuntura de la celebración de la paz, un hecho conmocionó al país. El 19 de febrero fueron ejecutados tres diputados salvadoreños ${ }^{6}$ del Parlamento Centroamericano en tierras guatemaltecas. Si bien este hecho no provocó mayores roces o conflictos graves entre ambos países, sí causó que tanto autoridades como el propio presidente exigieran al vecino país una investigación para esclarecer los hechos. Las investigaciones llevaron a que diversos funcionarios de gobierno, entre ellos el jefe de la unidad contra el crimen organizado de la Policía de Guatemala, y otros tres agentes de la misma unidad, fueran capturados $^{7}$ por su vinculación con el crimen. A pesar de que este hecho fue vinculado con el narcotráfico de Guatemala, al cierre del año los acontecimientos no se terminaban de esclarecer, pero las investigaciones señalaban la existencia de vínculos entre estructuras del crimen organizado y niveles de la institucionalidad estatal.

Con todo, el elemento que marcó más fuertemente la dinámica política del año fueron los preparativos para las elecciones de 2009. Incluso desde finales de 2006, las especulaciones en torno a la creación de alianzas partidarias ya estaban en la agenda de discusiones. El triunfo de gobiernos de izquierda en varios países del continente y en especial la llegada del FSLN al gobierno de Nicaragua, propició que tempranamente los partidos de derecha comenzaran a especular sobre posibles alianzas capaces de frenar un potencial triunfo de la izquierda. En este sentido, ARENA y el Partido de Conciliación Nacional (PCN) dejaron entrever una posible coalición a fin de unificar a la derecha. No obstante, meses más tarde ARENA ratificó su posición de no tener disposición a compartir fórmulas presidenciales con otros partidos; y la especulación sobre posibles candidatos, algunos de ellos funcionarios actuales de gobierno y otros funcionarios del partido inició. En concreto, René Figueroa, actual ministro de Seguridad y director de ideología del partido ARENA, manifestó su interés en convertirse en el candidato del partido. También la vicepresidenta actual, Ana Vilma de Escobar, dejó ver su interés ofreciendo una conferencia de prensa el mismo día en que el FMLN oficializaba su fórmula presidencial.

Del lado de la oposición, algunos partidos también dejaron entrever posibilidades de alianzas. El FDR y el PDC, por ejemplo, hablaron de una posible alianza presidencial, sin embargo el Secretario General del PDC pronto desestimó dichas posibilidades. En relación al FMLN, hubo especulaciones en torno a los posibles candidatos, pero no fue hasta octubre que de manera sorpresiva, oficial y renunciando al tradicional mecanismo de elecciones primarias, dio a conocer su fórmula presidencial. Cabe señalar que, a diferencia de otras contiendas electorales, el FMLN anunció con mucho tiempo de antelación y antes que ningún partido a sus candidatos. La fórmula oficializada está integrada por el periodista Mauricio Funes y el actual jefe de fracción legislativa, Salvador Sánchez Cerén. En cuanto a Funes, cuyo nombre se manejó como potencial candidato en las elecciones de 2004, es una figura pública ajena a las estructuras partidarias, pero reconocida por su línea crítica, con quien se espera atraer el voto indeciso, como el de oposición no partidaria. Sánchez Cerén, por el contrario, es uno de los líderes históricos del FMLN desde su periodo de

6 Eduardo José D’aubuisson Munguía, William Rizziery Pichinte y José Ramón Gonzáles Rivas. Junto con ellos el chofer Gerardo Napoleón Ramírez.

7 "Jefe policial detenido por asesinato de diputados", El Faro, 22 febrero, 2007. 
frente guerrillero y con el que se espera mantener la unidad de las bases tradicionales del partido. ${ }^{8}$

Este ambiente que inició de manera prematura, también incluyó la participación de otros actores. Por un lado, del sector empresarial y de manera independiente, Arturo Zablah, quien formó parte del gabinete económico de las dos primeras administraciones de ARENA, lanzo una iniciativa orientada a promover una potencial candidatura y a buscar alianzas con algún partido. Por otro lado, por parte de algunos alcaldes de los partidos FMLN, FDR, PCD y PCN surgió el interés de formar una alianza que les permitiera competir en las elecciones de 2009. No obstante la dinámica y el interés, ninguna de estas dos iniciativas llegó a concretarse en algún tipo de alianza. Por un lado, Zablah declinó su postulación a mediados de diciembre al no haber logrado una alianza con los partidos; por el otro, "los líderes por el cambio", como se hicieron llamar los alcaldes, abandonaron sus acercamientos y dejaron de pronunciarse.

De esta forma, el año cerró con la nominación de la fórmula presidencial del FMLN y las especulaciones de candidatos en torno al resto de partidos. Dadas las condiciones en que se ha detonado el proceso, la situación permite pensar al menos dos cosas respecto de 2008: en primer lugar, que el nuevo año se concentrará privilegiadamente en los temas y problemas político electorales, especialmente en aquellos asociados a la dinámica de polarización marcada por los dos partidos más grandes y, en segundo, que la discusión y las campañas electorales estarán fuertemente marcadas por el relevamiento del perfil de los candidatos en contienda.

\section{LA COYUNTURA SOCIAL}

Como lo ha sido casi invariablemente tras la firma de los Acuerdos de paz, el clima de inseguridad y violencia social siguió siendo el factor central del clima social en el país. A ello se ha sumado en 2007 preocupantes acontecimientos de conflictividad social que evidencian múltiples malestares sociales $\mathrm{y}$, a su vez, permiten observar tendencias autoritarias en el tratamiento estatal de los problemas y la protesta social.

Dos hechos importantes de destacar en este orden. En primer lugar, los fuertes disturbios que al inicio y final del primer semestre provocaron los vendedores ambulantes de los municipios de Apopa y San Salvador y que llevaron al enfrentamiento entre éstos y la policía. El motivo de los enfrentamientos, para ambos casos, fue el decomiso de mercadería pirata efectuado por las autoridades. El enfrentamiento más sintomático fue el registrado en el Centro Histórico de San Salvador, pues el mismo produjo serios destrozos a la propiedad y, a su vez, se procedió a abrir proceso judiciales contra vendedores detenidos argumentando la aplicabilidad de la Ley Antiterrorista, aprobada en septiembre de 2006, bajo Decreto Legislativo $N^{\circ} 108$ publicada en el Diario Oficial No 193 del 17 de octubre de 2006. 
El segundo conflicto relevante estuvo motivado por el anuncio de la Política Nacional de Descentralización del Agua por parte del Presidente de la República, Antonio Saca. El 2 de julio, en momentos que el presidente pronunciaría un discurso asociado a esta temática en el municipio de Suchitoto, diversas organizaciones comunitarias y sociales realizaron acciones de protesta (toma de calles de acceso al lugar y concentraciones ciudadanas en la plaza central del municipio) por considerar que dicha política representa una amenaza de privatización del acceso al agua. Las movilizaciones provocaron una fuerte respuesta policial de persecución y captura de los manifestantes y la intervención de unidades del ejército. Como resultado, 14 personas fueron capturadas las cuales eventualmente serían juzgadas bajo los términos de la ley antiterrorista. ${ }^{9}$

Si bien finalmente los detenidos en ambos casos no fueron juzgados por actos terroristas, sino más bien por el delito de desórdenes públicos, lo cierto es que los acontecimientos despertaron serias preocupaciones por sus graves consecuencias. En el caso de las protestas sociales en Suchitoto, el desproporcionado uso de la fuerza en la respuesta gubernamental despertó incluso serias preocupaciones inclusive en actores de la comunidad internacional.

Con todo, como se ha señalado, la inseguridad ciudadana y la violencia continuó siendo el principal factor del clima y preocupación social. Desde 2002, fuera ya del contexto de guerra, y de acuerdo a los datos de la Policía nacional Civil, la tasa de homicidios en ningún año ha sido menor de 30 homicidios por cada 100 mil habitantes. Visto desde otro ángulo, los datos policiales indican desde aquel año, el promedio de homicidios diarios oscilan entre 7 y 10 según el periodo. ${ }^{10}$ En este orden, el año 2007 no fue la excepción: por lo menos para los cinco primeros meses del año, la PNC contabilizó 1.477 homicidios, lo que da un promedio de 9 homicidios diarios. ${ }^{11}$

Un rasgo característico del fenómeno de la delincuencia y violencia que se vive en el país, ha sido la participación cada vez más acentuada de las pandillas juveniles o maras, las cuales desde el 2003 han sido el objeto de programas y leyes represivas y poco eficaces como el Plan Mano Dura y el Plan Súper Mano Dura que continua vigente. Durante 2007, la Unidad de Justicia Juvenil reveló que el número de menores de edad que cometen delitos ha ido en aumento en los últimos años. El delito en el que más se han visto involucrados es en el de extorsión, pues, según el subdirector de la PNC, muchos pandilleros están enviando a menores de edad a recoger el dinero de la extorsión. ${ }^{12}$

La situación de la violencia social es tal que la cotidianeidad y preocupaciones ciudadanas han estado permanentemente afectadas por el fenómeno. De acuerdo una encuesta realizada por el Instituto Universitario de Opinión Pública de la Universidad José Simeón Cañas y conocida en el mes de noviembre, el $52,4 \%$ de los entrevistados señala que la delincuencia, pese a las acciones gubernamentales, ha aumentado respecto del año anterior; un 24,7\% dice que siguió igual, y un 22,9\% señala que ésta disminuyó. A su vez, el 19,4\% de la ciudadanía declaró haber sido víctima de un hecho delincuencial de forma directa. ${ }^{13}$

\footnotetext{
“Crónica del mes", en Revista ECA No 705, julio 2007, p. 590.

Ver: Loya, Nayelly y Carlos G. Ramos (2007). “Delincuencia, democracia y gobernabilidad”. En Debates Serie de Investigación $\mathrm{N}^{\circ}$ 3. El Salvador: FLACSO-Programa El Salvador.

"En cinco meses 1,477 muertes", El Diario de Hoy, 18 junio, 2007.

"Se ha procesado a 2.349 menores en sólo seis meses", El Diario de Hoy, 30 octubre, 2007.

Instituto Universitario de Opinión Pública, IUDOP (2007). Boletín de Prensa, año XXII, noviembre, $\mathrm{N}^{\circ} 2$.
} 


\section{LA COYUNTURA ECONÓMICA}

Durante 2007, según datos del Banco Central de Reserva, la economía salvadoreña obtuvo la mayor tasa de crecimiento de los últimos doce años: 4,7\% del PIB. Este repunte de la economía, según la misma fuente, ha sido impulsado principalmente por el crecimiento en los sectores agropecuario $(8,8)$, financiero $(5,4)$, comercio $(5,3)$, transporte y comunicaciones $(5,1)$, e industria manufacturera $(3,7)$. El Gráfico 1 presenta la evolución del Producto Interno Bruto para los últimos 12 años ${ }^{14}$.

Gráfico 1: Producto Interno Bruto, Tasa de Crecimiento Anual.

A precios constantes de 1990

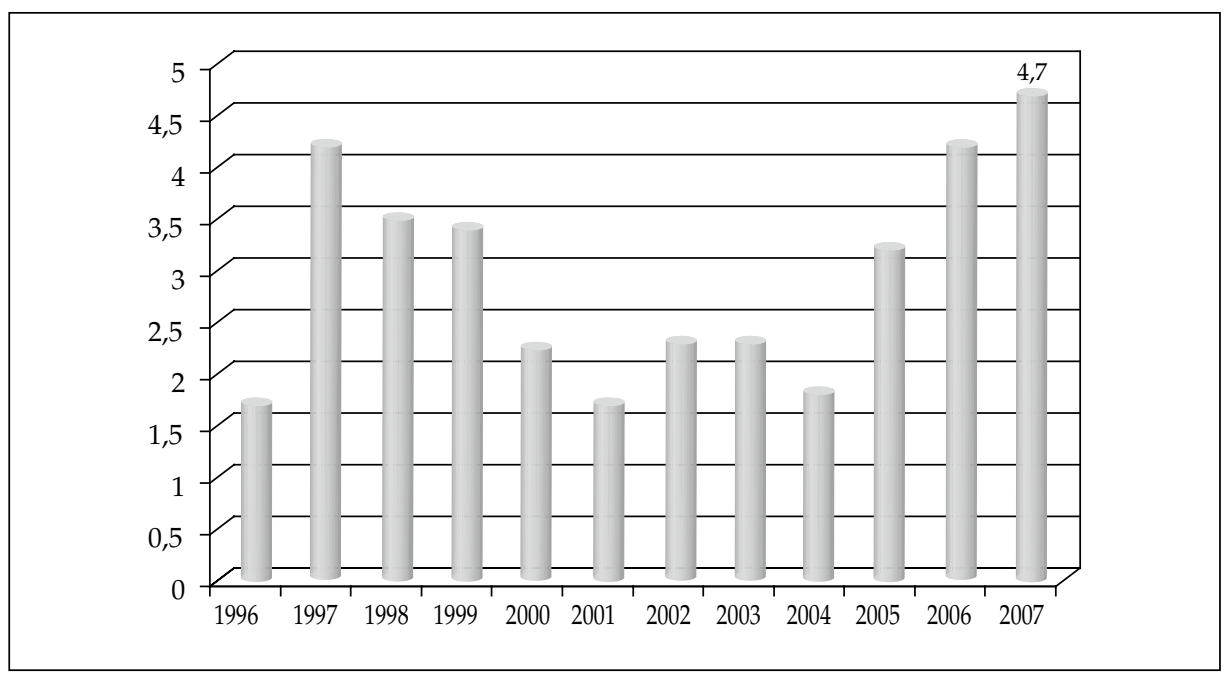

Fuente: Banco Central de Reserva (2007). "Situación económica 2007 y perspectivas 2008". Documento en internet: http:/ /www.bcr.gob.sv/Situaci\%F3n\%20Econ\%F3mica\%202007\%20y\%20 perspectivas\%202008.pdf

Entre los factores que estarían detrás de ese favorable desempeño en la economía, el $\mathrm{BCIE}^{15}$ ubica principalmente un robusto dinamismo en el comercio exterior, un mayor fortalecimiento de la recaudación tributaria y una mayor disciplina fiscal. Adicionalmente debe mencionarse el papel que han jugado las remesas familiares (18,7\% del PIB), pues éstas contribuyeron nuevamente a dinamizar el consumo privado y aliviar el efecto del alza del precio internacional del petróleo en la cuenta corriente, que registró un déficit del $4,6 \%$ del PIB ${ }^{16}$.

14 Banco Central de Reserva (2007). “Situación económica 2007 y perspectivas 2008”. Documento en Internet: http:/ /www. bcr.gob.sv/Situaci\%F3n\%20Econ\%F3mica\%202007\%20y\%20perspectivas\%202008.pdf

15 Banco Centroamericano de Integración Económica (2007). “Tendencias y perspectivas macroeconómicas 2007: Centroamérica y República Dominicana”. Documento en Internet: http:/www.bcie.org

16 Comisión Económica para América Latina y el Caribe (CEPAL) (2007). Balance preliminar de las economías de América Latina y el Caribe 2007. Chile: CEPAL. 
En cuanto a las exportaciones, debe mencionarse que en marzo se cumplió un año de la entrada en vigencia del Tratado de Libre Comercio con Estados Unidos. Según la Ministra de Economía, Yolanda de Gaviria, el crecimiento económico y el aumento de las exportaciones se debe a dicho tratado. ${ }^{17}$ Lo cierto es que las exportaciones han sido lideradas por los bienes no tradicionales (alcohol etílico absoluto, medicamentos preparados, hierro, manufacturas y productos de papel, entre otros) que han crecido en 14,8\% tanto las destinadas a Centroamérica como al resto del mundo. Estas exportaciones son las que muestran el mayor valor y tasa de crecimiento, inclusive superando a la maquila que durante muchos años fue el principal rubro exportador.

En cuanto a los precios, los mismos se han visto fuertemente afectados por el alza en los precios internacionales de los Hidrocarburos. De hecho la factura petrolera de $2007 \mathrm{se}$ estimó en \$ 1.500 millones de dólares, la cifra más alta desde el 2000. Adicionalmente, este hecho ha impactado el alza de precios de los granos como el maíz amarillo que es un insumo para la alimentación de ganado y aves lo que ha provocado una subida de precios de las carnes ${ }^{18}$. No obstante las implicaciones indicadas, la tasa de inflación se registró en $5,5 \%$, la más baja en la región. ${ }^{19}$

Para atenuar el impacto de los incrementos, en especial al sector del transporte público, el gobierno anunció, a principios del mes de diciembre, el denominado plan "Alianza por la familia". Dicho programa incluye 19 medidas divididas en dos grandes grupos. Las primeras tienen que ver con los servicios que presta el Estado e incluyen eliminación de ciertos cobros (eliminación de cuotas a nivel bachillerato de secundaria, ayuda al agro, seguro social, etc.); y las segundas implican un mayor control sobre el sector privado, para evitar abusos y cobros indebidos a los consumidores (incluyen un mayor control sobre el sistema financiero, dotar de más herramientas a la Defensoría del Consumidor para evitar cobros excesivos, medidas que involucran a la telefonía y al sector de la energía eléctrica). ${ }^{20}$ Lo cierto es que al concluir el año, era aún muy prematuro para poder tener una valoración del plan y sus resultados.

\section{PODER EJECUTIVO}

De acuerdo al artículo 150 de la Constitución, el Poder Ejecutivo está integrado por el presidente, el vicepresidente, los ministros y viceministros de Estado y sus funcionarios dependientes. El presidente y vicepresidente son elegidos bajo la fórmula de mayoría absoluta de votos, por un período de cinco años. Le corresponde al presidente nombrar, remover, aceptar denunciar y conceder licencias a los ministros y viceministros (Art. 162). El gabinete está conformado por doce ministerios, ocho secretarías, diecisiete presidencias, dos directores de diversas instituciones y cinco superintendencias. Adicionalmente el

Semanario Proceso, No 1232, marzo 7, 2007.

Cámara de Comercio e Industria de El Salvador (2007). Comportamiento de la economía en El Salvador durante el tercer trimestre de 2007. Documento en Internet: http:/ / www.camarasal.com/panorama.php

Banco Central de Reserva (2007). "Situación económica 2007 y perspectivas 2008".

"19 medidas para alivio a familias", La Prensa Gráfica, 4 diciembre, 2007. 
actual Presidente de la República, a lo largo de su gobierno, ha creado diferentes figuras (Comisionada Presidencial para la Gobernabilidad, para la agricultura, para la defensoría del consumidor, para el área social y para el café) con el objeto de atender de manera directa aspectos importantes de su gobierno. En cuanto a la composición de género, el actual gabinete está conformado en su mayoría por hombres, sólo hay dos ministerios a cargo de mujeres, el de Economía y el de Educación.

En el actual gobierno, el gabinete ha estado integrado, en su mayoría, por figuras del o muy cercanas al partido ARENA (ver anexo 1). Los ministerios de mayor peso como el de gobernación, seguridad pública y relaciones exteriores son ocupados por personas que en determinados momentos han tenido altos puestos dentro del partido. Esta articulación partido-gobierno es tal que incluso el Presidente de la República funge al mismo tiempo como presidente de ARENA. Esta situación por un lado, le ha permitido incidir tanto en los comicios legislativos de 2006 -donde realizó campaña abierta a favor de su partido-, como en el actual proceso para los comicios de 2009 llamando "a todo el país" a hacer una alianza para enfrentar a la izquierda. ${ }^{21}$ Por el otro, tal situación ha sido también centro de críticas y motivo de debilitamiento de su credibilidad ante sectores de la población. Al inicio de su gestión, en agosto de 2004, la calificación otorgada por las encuestas al presidente era de 7,27; en mayo de 2005 fue de 6,56; para mayo 2006 tuvo 6,23, y en mayo de 2007, la calificación fue de 5,7122, la más baja de todo su período.

El gabinete ha sufrido diversos cambios desde su composición en 2004. Algunos de ellos se dieron como producto de redefiniciones estructurales en la organización gubernamental como fue el cambio en el 2006 de René Figueroa del Ministerio de Gobernación, al Ministerio de Seguridad Pública y Justicia. Sin embargo, los cambios efectuados en 2007 parecen derivarse más bien de problemas coyunturales o, peor aún, de ciertas fracturas al interior del partido. Puede señalarse aquí una coyuntura de denuncias periodísticas sobre el manejo de ciertas carteras de Estado, que estuvieron acompañadas de hechos como la renuncia del ministro de Obras Públicas, en los primeros días del mes de enero, quien fue sustituido por Jorge Nieto, quien se desempeñaba en ese momento como superintendente de SIGET. Otros cambios parecen haberse dado por situaciones más claras de conflictos y presiones internas en el gobierno o el partido. Si bien la sustitución del viceministro de Obras Públicas puede citarse, el caso de referencia central fue la renuncia del Secretario Técnico de la Presidencia, Eduardo Zablah -artífice de medidas que le permitieron al gobierno enfrentar vetos parlamentarios para adquirir deuda, y principal responsable de obtener los Fondos del Milenio-, quien dimitió -según algunos medios informativosdebido a una campaña de desprestigio que se habría orquestado en su contra. ${ }^{23}$

\footnotetext{
"Saca: Todos deben unirse contra el FMLN", La Prensa Gráfica, 28 junio, 2007.

Semanario Proceso $\mathrm{N}^{\mathrm{o}} 1243$, mayo 30, 2007. p.1

"El gabinete fracturado", El Faro, 31 diciembre, 2007. De acuerdo a diversos medios de comunicación, en el gabinete del presidente Saca se pueden dibujar dos grupos, el de los colaboradores más cercanos del presidente y el de los "técnicos".
} 


\section{PODER LEGISLATIVO}

La Asamblea legislativa es un cuerpo colegiado compuesto por 84 diputados elegidos (Art. 121 Constitución) bajo el principio de representación proporcional por un período de tres años. Los diputados, dentro de la Asamblea se dividen en grupos de trabajo o comisiones legislativas, nombrados por la Junta Directiva. Estas se crean con determinada especialidad en las distintas áreas del quehacer legislativo, siendo la presidencia de la Asamblea la que distribuye dicho trabajo. ${ }^{24} \mathrm{Como}$ se aprecia en la Tabla 5, las presidencias de las comisiones son asignadas a partidos políticos. En el periodo legislativo 2006-2009, los partidos más grandes presiden igual cantidad de comisiones, siguiéndole el $\mathrm{PCN}$ y luego el PDC. El CD, partido que goza de representación parlamentaria, no preside ninguna comisión. Cabe señalar que algunas de las comisiones más importantes, como Hacienda y Relaciones Exteriores son dirigidas por el partido de gobierno.

Tabla 5: Comisiones legislativas

\begin{tabular}{llc}
\hline Comisión & Partido que la preside \\
\hline 1. & Comisión de Asuntos Municipales & PCN \\
2. Comisión de Cultura y Educación & FMLN \\
3. Comisión de Defensa & ARENA \\
4. Comisión de Economía y Agricultura & FMLN \\
5. Comisión Financiera & ARENA \\
6. Comisión de Hacienda y Especial del Presupuesto & ARENA \\
7. Comisión de Justicia y Derechos Humanos & FMLN \\
8. Comisión de Turismo, Juventud y Deporte & ARENA \\
9. Comisión de La Familia, La Mujer y La Niñez & PDC \\
10. Comisión de Legislación y Puntos Constitucionales & ARENA \\
11. Comisión de Modernización & PCN \\
12. Comisión de Obras Públicas & FMLN \\
13. Comisión Política & PCN \\
14. Comisión de Salud, Medio Ambiente y Recursos Naturales & PCN \\
15. Comisión de Reformas Electorales y Constitucionales & FMLN \\
16. Comisión de Relaciones Exteriores e Integración & ARENA \\
17. Centroamericana y Salvadoreños en el Exterior & \\
18. Comisión de Seguridad Pública y Combate a la & PCN \\
\hline
\end{tabular}

Fuente: Página Web de la Asamblea Legislativa de El Salvador.

24 En las comisiones se toman decisiones o acuerdos por consenso de todos los diputados o la mayoría. Las comisiones eligen un presidente, un secretario y un relator. 
La actual configuración parlamentaria está definida por 34 escaños de ARENA, 32 del FMLN, 10 del PCN, 6 de PDC y 2 de CD. De estos parlamentarios, 70 son hombres y 14 mujeres. Igual que en asambleas anteriores, ningún partido tiene escaños suficientes como para controlar el órgano legislativo y ello ha obligado a que los partidos mayoritarios se encuentren sistemáticamente en la necesidad de conformar alianzas legislativas.

De hecho, esta condición fue uno de los factores que propiciaron parálisis en torno a urgentes reformas en materia electoral: no se discutió la implementación del voto residencial, ni el financiamiento a los partidos políticos y tampoco la regulación de las campañas electorales. Sin embargo, gracias a las alianzas logradas, se aprobó la separación de elecciones en los comicios de 2009, dejando las elecciones legislativas y de concejos municipales en enero y las presidenciales en marzo. Asimismo, sin mayor discusión fueron aprobadas por los partidos ARENA, PDC y PCN una serie de reformas electorales que lejos de facilitar el proceso electoral, podrían tornarlo confuso o motivar prácticas manipuladoras y fraudulentas. Entre las nuevas reformas se encuentran la eliminación de la firma y sello del presidente de la junta Receptora de Votos en las papeletas de votación como factor de validación del voto, así como la posibilidad de validar papeletas que aparezcan con tachones fuera de las banderas de los partidos políticos, entre otras. ${ }^{25}$

Lo cierto es que en ausencia de mayoría, las alianzas han sido decisivas en la dinámica parlamentaria. Durante 2007 las mismas permitieron al gobierno la aprobación de la Ley de creación del sistema Nacional de Salud, el Fideicomiso para la seguridad y educación y el presupuesto general del año 2008. La aprobación del fideicomiso ${ }^{26}$, que fue la figura utilizada por el Ejecutivo ante la negativa del FMLN y el CD de aprobar los préstamos concedidos por el Banco Mundial y el Banco Interamericano de Desarrollo, fue probablemente una de las situaciones de mayor tensión entre los órganos de gobierno y entre los partidos, y propició mutuas campañas de acusaciones entre ARENA y el FMLN.

\section{EVALUACIÓN GENERAL SOBRE EL FUNCIONAMIENTO Y CALIDAD DE LA DEMOCRACIA}

En general, el proceso democrático abierto en 1992 ha permitido establecer una relativa estabilidad social y política, así como mantener y fortalecer el núcleo de la reforma de institucionalidad diseñada en los Acuerdos de Paz. Sin embargo, pese al avance en materia electoral y del respeto a las libertades y derechos humanos, la democracia en construcción parece estar adoleciendo cada vez de espacios y mecanismos de diálogo y concertación entre las fuerzas políticas y, más importante aún, de voluntad concertadora. En este sentido, el 2007 fue un año en que las altas posibilidades de buscar nuevos acuerdos políticos -que se vislumbraron a principios del año-fueron truncadas por las confrontadas visiones de país de la clase política y por su comportamiento polarizado.

25 "Fin de año con reformas electorales", El Faro, 31 diciembre, 2007.

26 A finales del año 2006 el Ejecutivo comenzó a presionar para que la Asamblea aprobara el préstamo que financiaría algunos programas de gobierno e instituciones del Estado. Ver: Semanario Proceso N ${ }^{\circ} 1232$. 
Lo que deja 2007 permite pensar que 2008 será agitado políticamente hablando. Muy probablemente, el proceso electoral pondrá a prueba la unidad interna de los principales partidos políticos y, a la vez, someterá al país a mayor nivel de polarización política. El mayor riesgo de 2008 es, en este sentido, que las urgencias electorales subordinen los temas y debates pendientes que el país tiene, y que 2008 sea un año desperdiciado para el desarrollo social y democrático.

\section{REFERENCIAS}

Banco Central de Reserva. 2007. "Situación económica 2007 y perspectivas 2008". [En línea] <http:// www.bcr.gob.sv/Situaci\%F3n\%20Econ\%F3mica\%202007\%20y\%20perspectivas\%202008.pdf $>$. [Consulta: 1-2-2008]

Banco Centroamericano de Integración Económica. 2007. “Tendencias y perspectivas macroeconómicas 2007: Centroamérica y República Dominicana". [En línea] <http:/www.bcie.org> [Consulta: 1-2-2008]

Cámara de Comercio e Industria de El Salvador. 2007. Comportamiento de la economía en El Salvador durante el tercer trimestre de 2007. [En línea] <http:/ / www.camarasal.com/panorama.php $>$ [Consulta: 1-2-2008]

Córdova, Ricardo; Carlos G. Ramos y Nayelly Loya (2007)."La contribución del proceso de paz a la construcción de la democracia en El Salvador (1992-2004)". En: Azpuru, Dinorah, Ligia Blanco, Ricardo Córdova, Nayelly Loya, Carlos G. Ramos y Adrián Zapata. Construyendo la democracia en sociedades posconflicto. Guatemala y El Salvador. Un enfoque comparado. Guatemala: IDRC\&CRDI, F\&G Editores.

El Diario de Hoy. 2007. Se ha procesado a 2.349 menores en sólo seis meses. 30 octubre.

El Diario de Hoy. 2007. En cinco meses 1.477 muertes. 18 junio.

El Faro. 2007. El gabinete fracturado. 31 diciembre.

El Faro. 2007. Fin de año con reformas electorales. 31 diciembre.

El Faro. 2007. Jefe policial detenido por asesinato de diputados. 22 febrero.

Instituto Universitario de Opinión Pública, IUDOP. (2007). Boletín de Prensa año XXII, N²

La Prensa Gráfica. 2007. Saca: Todos deben unirse contra el FMLN. Junio.

La Prensa Gráfica. 2007. 19 medidas para alivio a familias. 4 diciembre.

La Prensa Gráfica. 2007. ARENA lidera intención de voto". 28 agosto.

Loya, Nayelly. 2006. Distribución territorial del comportamiento electoral en elecciones de Concejo Municipal. Tesis para optar al grado de Maestría. Universidad Centroamericana José Simeón Cañas.

Loya, Nayelly y Carlos G. Ramos. 2007. "Delincuencia, democracia y gobernabilidad”. En Debates Serie de Investigación $N^{\circ}$ 3. El Salvador: FLACSO-Programa El Salvador.

Revista ECA. 2007. Crónica del mes. Julio: 590.

Semanario Proceso $\mathrm{N}^{\circ} 1229$, febrero 14, 2007. Universidad Centroamericana José Simeón Cañas.

Semanario Proceso $\mathrm{N}^{\circ} 1232$ Universidad Centroamericana José Simeón Cañas.

Semanario Proceso $N^{\circ} 1243$, mayo 30, 2007. Universidad Centroamericana José Simeón Cañas.

Semanario Proceso $N^{\circ} 1260$, octubre, 2003. Universidad Centroamericana José Simeón Cañas.

Semanario Proceso No 1232, marzo 7, 2007. Universidad Centroamericana José Simeón Cañas.

Tribunal Supremo Electoral, 2006. 
Anexo 1: Gabinete presidencial

\begin{tabular}{|c|c|c|c|}
\hline Ministerio & Puesto & Titular a 2007 & Antes \\
\hline \multirow{3}{*}{$\begin{array}{l}\text { Ministerio de Relaciones } \\
\text { Exteriores }\end{array}$} & Ministro & $\begin{array}{c}\text { Francisco E. Laínez } \\
\text { Rivas }\end{array}$ & \\
\hline & Viceministro & $\begin{array}{c}\text { Eduardo Cálix } \\
\text { López }\end{array}$ & \\
\hline & $\begin{array}{l}\text { Viceministra de } \\
\text { Relaciones Exteriores } \\
\text { para los salvadoreños } \\
\text { en el Exterior }\end{array}$ & Margarita Escobar & \\
\hline \multirow[t]{2}{*}{ Ministerio de Gobernación } & Ministro & $\begin{array}{l}\text { Juan Miguel } \\
\text { Bolaños }\end{array}$ & $\begin{array}{l}\text { René M. } \\
\text { Figueroa } \\
\text { Figueroa } \\
\end{array}$ \\
\hline & Viceministro & $\begin{array}{c}\text { Mario Alberto } \\
\text { Tenorio }\end{array}$ & Silvia Alguilar \\
\hline \multirow{2}{*}{$\begin{array}{l}\text { Ministerio de Seguridad Pública } \\
\text { y Justicia }\end{array}$} & Ministro & $\begin{array}{l}\text { René M. Figueroa } \\
\text { Figueroa }\end{array}$ & \\
\hline & Viceministro & Astor Escalante & \\
\hline \multirow{2}{*}{ Ministerio de Hacienda } & Ministro & $\begin{array}{l}\text { William Jacobo } \\
\text { Hándal Hándal }\end{array}$ & \\
\hline & Viceministro & $\begin{array}{c}\text { Rafael Ernesto } \\
\text { Mercado }\end{array}$ & \\
\hline \multirow{3}{*}{ Ministerio de Economía } & Ministra & Yolanda de Gavidia & \\
\hline & Viceministra & Johanna Hill & \\
\hline & $\begin{array}{l}\text { Viceministra de } \\
\text { Comercio e Industria }\end{array}$ & $\begin{array}{c}\text { Blanca Imelda Jaco } \\
\text { de Magaña }\end{array}$ & \\
\hline \multirow{3}{*}{ Ministerio de Educación } & Ministro & Darlyn Meza & \\
\hline & Viceministro & José Luis Guzmán & \\
\hline & $\begin{array}{l}\text { Viceministro de } \\
\text { Tecnología }\end{array}$ & $\begin{array}{c}\text { Carlos Benjamín } \\
\text { Orozco }\end{array}$ & \\
\hline \multirow{2}{*}{$\begin{array}{l}\text { Ministerio de la } \\
\text { Defensa Nacional }\end{array}$} & Ministro & $\begin{array}{c}\text { General Otto } \\
\text { Romero Orellana } \\
\end{array}$ & \\
\hline & Viceministro & $\begin{array}{l}\text { Gral. Ricardo G. } \\
\text { Abrego Abrego }\end{array}$ & \\
\hline \multirow{2}{*}{$\begin{array}{l}\text { Ministerio de Trabajo y } \\
\text { Previsión Social }\end{array}$} & Ministro & $\begin{array}{l}\text { José Roberto } \\
\text { Espinal Escobar }\end{array}$ & \\
\hline & Viceministra & $\begin{array}{c}\text { Carmen Elisa Sosa } \\
\text { de Callejas }\end{array}$ & \\
\hline \multirow{2}{*}{$\begin{array}{l}\text { Ministerio de Agricultura y } \\
\text { Ganadería }\end{array}$} & Ministro & $\begin{array}{l}\text { Mario Salaverria } \\
\text { Nolasco }\end{array}$ & \\
\hline & Viceministro & José Emilio Saudí & \\
\hline \multirow{2}{*}{$\begin{array}{l}\text { Ministerio de Salud Pública y } \\
\text { Asistencia Social }\end{array}$} & Ministro & $\begin{array}{c}\text { Jose Guillermo } \\
\text { Maza Brizuel }\end{array}$ & \\
\hline & Viceministro & $\begin{array}{l}\text { José Ernesto } \\
\text { Navarro Marín }\end{array}$ & \\
\hline
\end{tabular}




\begin{tabular}{|c|c|c|c|}
\hline Ministerio & Puesto & Titular a 2007 & Antes \\
\hline \multirow{4}{*}{ Ministerio de Obras Públicas } & Ministro & $\begin{array}{l}\text { Jorge Isidro Nieto } \\
\text { Menéndez }\end{array}$ & David Gutiérrez \\
\hline & Viceministro & $\begin{array}{l}\text { Sigifredo Ochoa } \\
\text { Gómez }\end{array}$ & $\begin{array}{l}\text { Óscar Miguel } \\
\text { Joya }\end{array}$ \\
\hline & $\begin{array}{l}\text { Viceministra de } \\
\text { Vivienda y Desarrollo } \\
\text { Urbano }\end{array}$ & $\begin{array}{c}\text { Etna Mabel Artiga } \\
\text { de Soundy }\end{array}$ & Francisco Vega \\
\hline & $\begin{array}{l}\text { Viceministro de } \\
\text { Transporte }\end{array}$ & Luis Felipe Moreno & $\begin{array}{l}\text { Mauricio } \\
\text { Chavarría }\end{array}$ \\
\hline \multirow[t]{2}{*}{ Ministerio de Medio Ambiente } & Ministro & $\begin{array}{l}\text { Carlos José } \\
\text { Guerrero }\end{array}$ & Hugo Barrera \\
\hline & Viceministro & $\begin{array}{l}\text { Roberto Alfonso } \\
\text { Escalante }\end{array}$ & \\
\hline \multirow[b]{2}{*}{ Ministerio de Turismo } & Ministro & Rubén Rochi Parker & \\
\hline & Viceministra & $\begin{array}{c}\text { Michelle Gallardo } \\
\text { de Gutiérrez }\end{array}$ & - \\
\hline
\end{tabular}

Glosario

\begin{tabular}{ll}
\hline PDC & Partido Demócrata Cristiano \\
FMLN & Frente Farabundo Martí para la Liberación Nacional \\
ARENA & Alianza Republicana Nacionalista \\
CD & Cambio Democrático \\
PCN & Partido de Conciliación Nacional \\
\hline
\end{tabular}

Partidos Políticos con representación legislativa, 2006-2009.

Carlos G. Ramos, Magíster en Sociología por la Universidad de Costa Rica. Es autor de diversas obras y artículos en torno a los problemas de gobernabilidad, transición política y democracia, y juventud. Actualmente se desempeña como Coordinador Académico de la Facultad Latinoamericana de Ciencias Sociales (FLACSO) de El Salvador.

(E-mail: cramos1@flacso.org.sv)

Nayelly Loya Marín, Magíster en Ciencia Política por la Universidad Centroaméricana “José Simeón Cañas". Actualmente se desempeña como investigadora en la Facultad Latinoamericana de Ciencias Sociales (FLACSO) de El Salvador.

(E-mail: nallely@flacso.org.sv) 
